\title{
Keragaman Bulu Babi (Echinoidea) di Perairan Pantai Pulau Merah Pesanggaran Banyuwangi
}

\author{
Aimatuzzahro, Agus Sufadjari, N. Nurchayati \\ Program Studi Biologi , Fakultas Matematika dan Ilmu Pengetahuan Alam \\ Universitas PGRI Banyuwangi \\ Email: zahrobcl@yahoo.co.id
}

\begin{abstract}
Echinoidea has found in many marine defferences. This invertebrates were usually live in individualisia or in groups. They are live in rough substrate like rock and coastal but there are small group of echinoidea has live in sandy and muddy subtrate. The purpose of this research was to obtain the diversity ofechinoideain pulau merah shore Banyuwangi this research has been done in july 2016. This research used transek quadrat methode, divide 3 station. Station 1 lie down in side bouder of cea water, station 2 lie down in the middle of sea water and station 3 lie down prorude from sea water. In each station divide in 3 transeks and every transecs there were 3 plot. The result of this research showed there were 4 luind of echinoidea, Trineustes gratilla, Echinometra mathaei, Diadema sitosum, Sea urchin. the most many quantities of echinoidea species that found al most in all of the station was Echinometra mathaei the most hig herst diversity indees was Trineustes gratilla in station $2\left(\mathrm{H}^{\prime}=1\right)$ in station $3\left(\mathrm{H}^{\prime}=1\right)$. In station $3\left(\mathrm{H}^{\prime}=1\right)$. The most highast dominancy andecs was Echinometra mathaei in station $2(\mathrm{D}=0,664)$

Key word : Echinoidea, Diversity, Dominancy, Pulau Merah
\end{abstract}

\section{PENDAHULUAN}

Pantai adalah kenampakan alam yang menjadi batas antara wilayah yang bersifat daratan dengan wilayah yang bersifat lautan. Wilayah pantai dimulai dari titik terendah air laut pada saat surut hingga arah ke daratan sampai batas jauh gelombang atau ombak menjangkau daratan. Tempat pertemuan antara air laut dengan daratan tadi dinamakan garis pantai (shore line). Garis pantai ini setiap saat berubah-ubah sesuai dengan perubahan pasang-surut air laut (Brusca and Brusca, 1990).

Perairan laut Indonesia kaya akan berbagai biota laut, baik flora maupun fauna. Pada ekosistem laut, hidup beranekaragam biota laut seperti ikan, Echinodermata (Holothuria sp, Synapta sp, Diadema sp, Arcbaster sp, Linckia sp), dan cacing 
(Polichaeta) (Bengen, 2004). Echinodermata merupakan fauna penghuni karang, menyatakan bahwa terumbu karang merupakan suatu ekosistem yang penting bagi kehidupan fauna echinodermata. Faktor yang menguntungkan bagi echinodermata di daerah terumbu karang adalah tersedianya tempat perlindungan berupa koloni karang hidup maupun karang mati (Alfiati dkk, 2007).

Wilayah Banyuwangi memiliki banyak kawasan pantai, salah satunya adalah pantai pulau merah. yang terletak di desa Pesanggaran Banyuwangi. pantai pulau merah memiliki ombak yang besar, karakteristik pantai pulau merah terletak pada pemandangan pulau yang ada didekat bibir pantai. Pantai pulau merah memiliki pulau yang berupa bebatuan karang dengan tinggi mencapai lebih dari $200 \mathrm{~m}$. Pantai Pulau Merah mempunyai garis pantai hingga lebih dari $3 \mathrm{~km}$. Garis pantai yang panjang tersebut dilengkapi dengan air yang jernih dan pasirnya yang putih dan lembut. Karakteristik ombaknya yang saling berbenturan membuat ombak Pantai Pulau Merah menjadi kecil ketika sampai di bibir pantai.

Echinodermata golongan Bulu babi (Echinoidea) adalah sumber daya hayati yang bernilai ekonomis dan digemari masyarakat. Bulu babi (Echinoidea) hidup di ekosistem terumbu karang dan memiliki nilai jual tinggi, karena Gonad atau telurnya yang dapat dimanfaatkan sebagai bahan makanan yang bergizi tinggi. Bulu babi(Echinoidea)banyak ditemukan di seluruh lautan, Biota ini biasanya hidup menyendiri maupun berkelompok, dan biasanya hidup pada subtrat yang keras seperti batu batuan atau terumbu karang, dan hanya sebagian kecil yang menghuni subtrat pasir dan lumpur. Kelompok tersebut khusus hidup pada teluk yang tenang dan perairan yang lebih dalam, sehingga kecil kemungkinan dipengaruhi ombak. Bulu babi (Echinoidea) yang banyak ditemukan diperairan terutama di karang laut dan bebatuan.Keberadaan Bulu Babi(Echinoidea) pada suatu ekosistem tidak lepas juga dari pengaruh faktor fisika kimia pada lingkungan tersebut. Bulu babi (Echinoidea) memiliki fisik pertahanan berupa duri yang membuat mereka cocok untuk bertahan dan melindungi diri dari organisme laut seperti moluska, udang, 
kepiting, polychaetes (cacing anelida), copepods (crustacea kecil), dan ikan, (Ayyagari dan Kondamudi, 2014).

Makanan dari Bulu babi(Echinoidea) adalah sponge, alga, lamun, dan detritus.Echinoidea yang besar adalah merupakan herbivore. Bulu babi (Echinoidea) memiliki10 kemampuan untuk memperbaiki kerusakan pada spina atau duri yang patah,meskipun perbaikannya tidak sampai selesai. Bulu Babi (Echinoidea) akan mempertahankan diri dari serangan musuh dengan mengeluarkan racun yang diproduksinya dan disalurkan melalui spina/ duri Bulu Babi (Echinoidea)dapat ditemui sampai kedalaman 10 meter dengan batas toleransi salinitas antara 30-34\% (Coleman, 1991).

Mengingat karakteristik pantai pulau merah yang banyak terdapat Bulu babi (Echinoidea) dan minimnya pemanfaatan Bulu Babi (Echinoidea) oleh masyarakat sekitar. Maka peneliti termotivasi melakukan penelitian dengan judul "Keragaman Bulu Babi (Echinoidea) Di Perairan Pantai Pulau Merah Pesanggaran Banyuwangi”.

\section{METODE PENELITIAN}

\subsection{Bahan dan Alat}

Penelitian ini dilakukan di perairan pantai Pulau Merah Pesanggaran Banyuwangi, identifikasi Bulu babi(Echinoidea) dilakukan di Laboratorium Biologi Fakultas Matematika dan ilmu Pengetahuan Alam Universitas PGRI Banyuwangi. bahan yang digunakan: Sampel Bulu Babi (Echinoidea)Alkohol 96\%. Alat yang digunakan:Transek 1x1 m² Refraktometer Alat tulis Kertas label Kamera Stoples plastic $\mathrm{pH}$ meter Alat Ukur (Meteran/tali rafia)GPS, Termometer batang

\subsection{Prosedur penelitian}

Pengambilan sampel dilakukan dengan metode transek kuadrat dengan lokasi penelitian dilakukan di tiga stasiun. Setelah ke 3 stasiun penelitian ditetapkan, selanjutnya ditetapkan garis transek dari garis pasang surut pantai ke kedalaman laut sebanyak 3 transek dengan jarak antar transek $10 \mathrm{~m}$. Untuk setiap transek diletakkan 3 plot dengan jarak antar plot $5 \mathrm{~m}$ yang diletakkan dengan letak yang lurus kedalam. 
Jarak antara stasiun adalah $10 \mathrm{~m}$. Ukuran plot yang digunakan adalah dengan ukuran 1x1, Sampel yang sudah didapat kemudian diambil dari dalam plot dan dimasukkan kedalam stoples sampel. Kemudian diberi label yang berisi keterangan jenis bulu babi dan tanggal pengambilan.

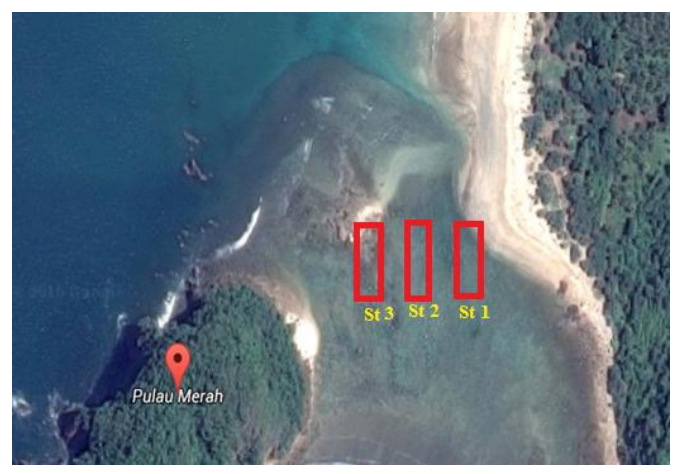

Gambar 2.1 Lokasi Penelitian

Keterangan:

St $1=$ stasiun 1

St $2=$ stasiun 2

St $3=$ stasiun 3

Karakteristik dari tempat yang dilakukan penelitian yaitu berada didekat pulau, serta mempunyai biota dan abiota laut yang baik. Peletakan stasiun 1 berada didekat garis pantai, stasiun 2 berada ditengah perairan, dan stasiun 3 berada di dekat pulau.

\subsection{Pengukuran parameter abiotik}

Pengukuran parameter abiotik perairan adalah suhu dengan menggunakan termometer batang yang dimasukkan ke dalam air kemudian hasil yang didapat dicatat. Pengukuran $\mathrm{pH}$ dengan menggunakan $\mathrm{pH}$ meter dengan cara yang sama seperti pengukuran suhu yaitu $\mathrm{pH}$ meter dimasukkan ke dalam air dan hasil yang diperoleh dicatat. Pengukuran salinitas dengan menggunakan refraktometer dengan cara meneteskan sampel air ke dalam refraktometer kemudian dicatat hasil yang diperoleh.

\subsection{Pengamatan Sampel Bulu Babi (Echinodea)}

Pengamatan sampel Bulu Babi (Echinodea) dilakukan di Laboratorium Program Studi Biologi Universitas PGRI Banyuwangi. Untuk pengamatan dilakukan

Inventarisasi serangan hama kutu putih (mealybug) pada tanaman singkong di kecamatan rogojampi dan $\quad$ |40 singojuruh 
pada ciri morfologi bulu babi (Echinoidea)

\subsection{Pengukuran Indeks Keragaman Bulu Babi (Echinodea)}

Keragaman menunjukkan keberagaman jenis. Keberagaman suatu biota air dapat ditentukan dengan menggunakan teori informasi Shannon - Wienner (H'). Tujuan utama teori ini adalah untuk mengukur tingkat keteraturan ketidakraturan dalam suatu sistem. Keragaman ditentukan berdasarkan indeks keragaman (jumanto, 2013). Dengan rumus:

$$
\mathrm{H}^{\prime}=-\Sigma \frac{n I}{N} \operatorname{Ln} \frac{\mathrm{nI}}{\mathrm{N}}
$$

Keterangan :

$$
\begin{aligned}
& \mathrm{H}^{\prime}=\text { Indeks keragaman } \\
& \mathrm{Ni}=\text { jumlah individu dari suatu jenis } \\
& \mathrm{N}=\text { jumlah total individu seluruh jenis } \\
& \text { In = logaritma nature } \\
& \text { Nilai h' }: \mathrm{H}^{\prime}<1=\text { keragaman rendah } \\
& 1 \leq \mathrm{H}^{\prime} \geq 3=\text { keragaman sedang } \\
& \mathrm{H}^{\prime}>3=\text { keragaman tinggi }
\end{aligned}
$$

\subsection{Pengukuran indeks keseragaman Bulu babi (Echinodea)}

Untuk mengetahui seberapa besar kesamaan penyebaran jumlah individu tiap jenis Echinoidea digunakan indeks keseragaman, yaitu dengan cara membandingkan indeks keseragaman, yaitu dengan cara membandingkan indeks keseragaman dengan nilai maksimumnya (fachrul, 2007). dengan rumus indeks Equitabilitas (E) $\mathrm{E}^{\prime}=\frac{H^{x}}{H \max }$ Keterangan:

$$
\begin{aligned}
& \mathrm{E}=\text { Indeks equitabilitas / indeks keseragaman } \\
& \mathrm{H}^{\prime}=\text { jumlah keseluruhan dari jenis } \\
& \mathrm{H} \text { max = keseragaman jenis maksimum }
\end{aligned}
$$

Indeks keseragaman berkisar antara 0-1. Bila keseragaman kurang dari 0,4 maka ekosistem tersebut berada dalam kondisi tertekan dan mempunyai keseragaman rendah. Jika indeks keseragaman antara 0,4 sampai 0,6 maka ekosistem tersebut kurang stabil dan mempunyai keseragaman sedang. Jika indeks keseragaman lebih 
dari 0,6 maka ekosistem tersebut dalam keadaan stabil dan mempunyai keseragaman tinggi.

\subsection{Pengukuran indeks dominansi bulu babi (Echinodea)}

Untuk menggambarkan jenis Bulu Babi (Echinodea) yang paling banyak ditemukan, dapat diketahui dengan menghitung nilai dominansinya. Dominansi dapat dinyatakan dalam indeks dominansi simpson (fachrul, 2007). Dengan rumus: $\mathrm{D}=\sum_{I=1}^{S}\left(\begin{array}{c}p i \\ p\end{array}\right) 2$

Keterangan:

$$
\begin{aligned}
& \mathrm{D}=\text { Indeks dominasi simpson } \\
& \mathrm{Pi}=\text { jumlah individu seluruh ke-i } \\
& \mathrm{P}=\text { jumlah total individu seluruh }
\end{aligned}
$$

Nilai indeks dominansi berkisar antara 0-1 semakin besar nilai indeks semakin besar kecenderungan salah satu jenis yang mendominansi populasi.

\subsection{Analisis data}

Data penelitian ini dianalisisdengan 2 cara, yaitu kuantitatif dan deskriptif analisis kuantitatif
a) Indeks keragaman $(\mathrm{H})$ menggunakan rumus $\mathrm{H}^{\prime}=-\Sigma \frac{\mathrm{n} I}{\mathrm{~N}} \operatorname{Ln} \frac{\mathrm{n} I}{\mathrm{~N}}$
b) Indeks keseragaman (E) menggunakan rumus $\mathrm{E}^{\prime}=\frac{H^{x}}{H \max }$
c) Indeks dominansi (D) menggunakan rumus $\mathrm{D}=\sum_{I=1}^{S}\left(\begin{array}{c}p i \\ p\end{array}\right) 2$

\subsection{Analisis Deskriptif}

Setelah data dianalisis secara kuantitatif, data dianalisis secara deskriptif yaitu dengan melihat kisaran indeks keragaman, keseragaman, dan dominansi setiap spesies. Keragaman berkisar Nilai h' : H'<1: keragaman rendah, $1 \leq \mathrm{H}^{\prime} \geq 3$ : keragaman sedang, $\mathrm{H}^{\prime}>3$ : keragaman tinggi. Keseragaman berkisar $\leq 0,4$ : keseragaman rendah, 0,4-0,6: keseragaman sedang, $\geq 0,6$ :keseragaman tinggi

\section{HASIL DAN PEMBAHASAN}

Kepadatan Nerita Undata Deskripsi karakteristik tempat pengamatan penelitian 
adalah keadaan atau struktur pantai tidak terkontaminasi dengan limbah masyarakat (Pantai dan perairannya bersih), Biota dan abiota laut terlihat masih alami serta memiliki karakter pasir putih dan halus. Berdasarkan hasil pengamatan dilapang yang dilakukan di Perairan pantai pulau Merah Pesanggaran Banyuwangi terdapat empat jenis bulu babi (Echinoidea) yaitu Trineustes gratilla, Echinometra mathaei, Diadema sitosum, dan Sea urchin. dapat dilihat pada gambar sebagai berikut.

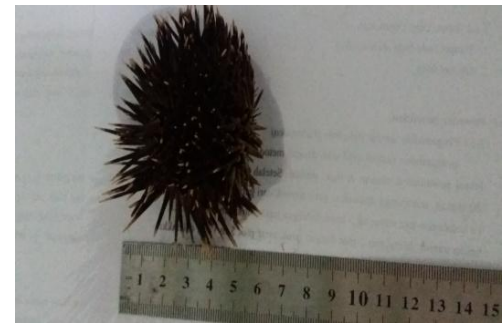

Echinometra mathaei

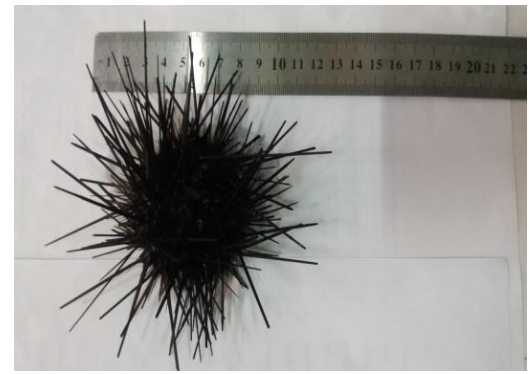

Diadema sitosum

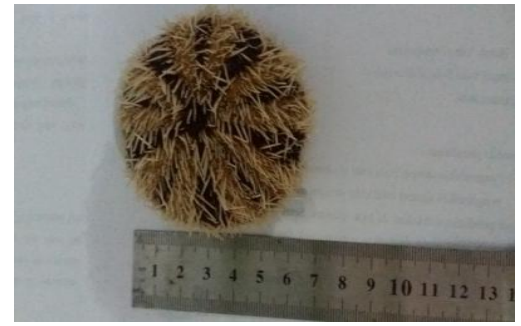

Trineustes gratilla

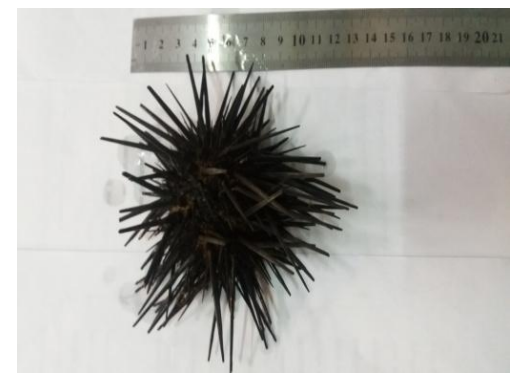

Sea urchin

Berdasarkan hasil pengamatan dari 3 stasiun, jumlah individu Bulu babi yang ditemukan yaitu dapat dilihat pada tabel 3.1 sebagai berikut.

Tabel 3.1 Jumlah Individu Bulu Babi yang Ditemukan

\begin{tabular}{cccc}
\hline & Stasiun 1 & Stasiun 2 & Stasiun 3 \\
\cline { 2 - 4 } $\begin{array}{c}\text { Nama } \\
\text { spesies }\end{array}$ & $\begin{array}{c}\text { Jumlah Bulu babi(Echinoidea) } \\
\text { yang ditemukan }\end{array}$ \\
\hline $\begin{array}{c}\text { Trineustes } \\
\text { gratilla }\end{array}$ & 2 & 1 & 1 \\
\hline $\begin{array}{c}\text { Echinometra } \\
\text { mathaei }\end{array}$ & 6 & 22 & 24 \\
\hline $\begin{array}{c}\text { Diadema } \\
\text { sitosum }\end{array}$ & 2 & 1 & 4 \\
\hline sea urchin. & - & 3 & 4 \\
\hline Jumlah & 10 & 22 & 33 \\
\hline
\end{tabular}

Inventarisasi serangan hama kutu putih (mealybug) pada tanaman singkong di kecamatan rogojampi dan singojuruh 
Berdasarkan tabel diatas, bahwa dari 3 stasiun tersebut, stasiun 3 terdapat paling banyak ditemukannya bulu babi dengan jumlah 33 individu dari 4 jenis bulu babi, individu terbanyak yaitu Echinometra mathaei. Pada stasiun 2 terdapat bulu babi dengan jumlah 22 individu dari 4 jenis bulu babi, individu terbanyak Echinometra mathaei. Pada stasiun 1 terdapat bulu babi dengan jumlah 10 individu dari 3 jenis bulu babi, individu yang paling banyak ditemukan yaitu Echinometra mathaei.

\subsection{Hasil Analisis Data}

Analisis data yang dilakukan dalam penelitian ini meliputi analisis indeks keragaman $(\mathrm{H})$, analisis indeks keseragaman (E), dan analisis indeks dominansi (D). Hasil analisis indeks keragaman ditunjukkan pada tabel sebagai berikut:

Tabel 3.2 Indeks Keragaman

\begin{tabular}{cccc}
\hline \multirow{2}{*}{ Nama Spesies } & \multicolumn{3}{c}{ Indeks keragaman (H) } \\
\cline { 2 - 4 } & Stasiun 1 & Stasiun 2 & $\begin{array}{c}\text { Stasiun } \\
3\end{array}$ \\
\hline $\begin{array}{c}\text { Trineustes } \\
\text { gratilla }\end{array}$ & 1,61 & 3,3 & 3,5 \\
\hline $\begin{array}{c}\text { Echinometra } \\
\text { mathaei }\end{array}$ & 0,51 & 0,2 & 0,32 \\
\hline $\begin{array}{c}\text { Diadema } \\
\text { sitosum }\end{array}$ & 1,61 & 3,3 & 2,11 \\
\hline Sea urchin & - & 2,2 & 2,11 \\
\hline
\end{tabular}

Berdasarkan tabel diatas, bahwa nilai $\mathrm{H}$ yang paling tinggi yaitu Trineustes gratilladi stasiun 3 yaitu sebesar 3,5hal ini menunjukkan bahwa Trineustes gratilla mempunyai keragaman tertinggi di Perairan pantai pulau merah dibandingkan dengan bulu babi yang lain.Echinometra mathaei mempunyai keragaman yang paling tinggi pada stasiun 1 sebesar 0,51. Diadema sitosum mempunyai keragaman paling tinggi pada stasiun 2 sebesar 3,3. Sea urchin mempunyai keragaman paling tinggi pada stasiun 3 sebesar 2,11. Hal ini menunjukkan bahwa keragaman paling rendah adalah Echinometra mathaei. 
Tabel 3.3 Indeks Keseragaman

\begin{tabular}{cccc}
\hline \multirow{2}{*}{ Nama Spesies } & \multicolumn{3}{c}{ Indeks keseragaman (E) } \\
\cline { 2 - 4 } & $\begin{array}{c}\text { Stasiun } \\
1\end{array}$ & $\begin{array}{c}\text { Stasiun } \\
2\end{array}$ & $\begin{array}{c}\text { Stasiun } \\
3\end{array}$ \\
\hline $\begin{array}{c}\text { Trineustes } \\
\text { gratilla }\end{array}$ & 0,7 & 1 & 1 \\
\hline $\begin{array}{c}\text { Echinometra } \\
\text { mathaei }\end{array}$ & 0,22 & 0,06 & 0,09 \\
\hline $\begin{array}{c}\text { Diadema } \\
\text { sitosum }\end{array}$ & 0,7 & 1 & 0,6 \\
\hline Sea urchin & - & 0,67 & 0,6 \\
\hline
\end{tabular}

Berdasarkan tabel tersebut, bahwa nilai E yang paling tinggi yaitu Trineustes gratilladi stasiun 2 dan 3 yaitu sebesar 1 hal ini menunjukkan bahwa Trineustes gratilla mempunyai keragaman tertinggi di Perairan pantai pulau merah dibandingkan dengan bulu babi yang lain. Echinometra mathaei mempunyai keseragaman yang paling tinggi pada stasiun 1 sebesar 0,22. Diadema sitosum mempunyai keseragaman paling tinggi pada stasiun 2 sebesar 1. Sea urchin mempunyai keseragaman paling tinggi pada stasiun 2 sebesar 0,67. Hal ini menunjukkan bahwa keseragaman paling rendah adalah Echinometra mathaei.

Tabel 3.4 Indeks Dominansi

\begin{tabular}{cccc}
\hline \multirow{2}{*}{$\begin{array}{c}\text { Nana } \\
\text { Spesies }\end{array}$} & $\begin{array}{c}\text { Stasiun } \\
1\end{array}$ & $\begin{array}{c}\text { Stasiun } \\
2\end{array}$ & Stasiun 3 \\
\hline $\begin{array}{c}\text { Trineustes } \\
\text { gratilla }\end{array}$ & 0,04 & 0,001 & 0,001 \\
\hline $\begin{array}{c}\text { Echinometra } \\
\text { mathaei }\end{array}$ & 0,36 & 0,664 & 0,529 \\
\hline $\begin{array}{c}\text { Diadema } \\
\text { sitosum }\end{array}$ & 0,04 & 0,001 & 0,015 \\
\hline Sea urchin & - & 0,012 & 0,015 \\
\hline
\end{tabular}

Berdasarkan tabel tersebut, bahwa nilai D yang paling tinggi yaitu Echinometra mathaei di stasiun 2 yaitu sebesar 0,664 hal ini menunjukkan bahwa Echinometra mathaei mempunyai dominansi tertinggi di Perairan pantai pulau merah dibandingkan dengan bulu babi yang lain. Trineustes gratilla mempunyai dominansi 
yang paling tinggi pada stasiun 1 sebesar 0,04. Diadema sitosum mempunyai dominansi paling tinggi pada stasiun 1 sebesar 0,04. Sea urchin mempunyai keseragaman paling tinggi pada stasiun 3 sebesar 0,015. Hal ini menunjukkan bahwa dominansi paling rendah adalah Trineustes gratilla.

\subsection{Hasil Pengukuran Parameter Lingkungan}

Berdasarkan hasil pengamatan yang dilakukan di perairan pantai pulau merah pesanggaran banyuwangi untuk mengetahui hasil pengukuran parameter lingkungan dengan parameter suhu, $\mathrm{pH}$, dan salinitas.

Tabel 3.4 Pengukuran Parameter Lingkungan

\begin{tabular}{cccc}
\hline & \multicolumn{3}{c}{ Kisaran nilai } \\
\cline { 2 - 4 } Parameter & Stasiun 1 & Stasiun 2 & Stasiun 3 \\
\hline $\mathrm{pH}$ & 7 & 7 & 7,1 \\
\hline Suhu & $30^{\circ} \mathrm{C}$ & $30^{\circ} \mathrm{C}$ & $30^{\circ} \mathrm{C}$ \\
\hline salinitas & $33 \%$ con & $34 \%$ & $34 \%$
\end{tabular}

Keragaman bulu babi diperairan pantai pulau merah dengan kondisi lingkungan yang sesuai dengan banyaknya terumbu karang akan memudahkan bulu babi untuk bertahan hidup dengan kondisi parameter lingkungan seperti suhu dengan kisaran 29 - $31^{\circ} \mathrm{C}$, pH dengan kisaran 7,1 - 7,5 dan salinitas dengan kisaran 30 - 35. Hasil pengukuran suhu dari ketiga stasiun yaitu $30^{\circ} \mathrm{C}$ yang masih sesuai untuk kehidupan bulu babi. Suhu perairan dapat mempengaruhi proses metabolisme dan siklus reproduksi bulu babi. Suhu sangat berpengaruh terhadap perkembangan singkat periode planktonik bulu babi yang mengakibatkan penurunan tekanan predasi dan juga mengubah hubungan antar populasi (Toha, 2007). Dengan begitu suhu yang berada di perairan pantai pulau merah pesanggaran banyuwangi masih layak untuk hidup bulu babi (Echinoidea).

Pengukuran $\mathrm{pH}$ dari ketiga stasiun yaitu antara 7 sampai 7,1 yang masih sesuai untuk kehidupan bulu babi. Nybakken (1992), mengatakan perairan laut maupun pesisir memiliki $\mathrm{pH}$ relatif lebih stabil dan berada dalam kisaran yang sempit, biasanya berkisar antara 7,7 - 8,4. sedangkan menurut Keputusan Menteri 
Lingkungan Hidup no.51 Tahun 2004 tentang baku mutu air laut untuk biota laut, pH normal untuk biota laut berkisar antara $7-8,5$, yang artinya perairan laut Dalam masih dalam kisaran normal dan baik untuk kehidupan bulu babi. Pengukuran $\mathrm{pH}$ yang ada di perairan pantai pulau merah pesanggaran banyuwangi masih sesuai untuk kehidupan bulu babi (Echinoidea).

Pengukuran salinitas dari ketiga stasiun yaitu antara $33-34 \%$ yang masih sesuai untuk kehidupan bulu babi. Salinitas dapat memiliki pengaruh berbeda pada pertumbuhan dan kelangsungan hidup larva dan juvenil bulu babi (Drouin dkk,1985). Keputusan Menteri Lingkungan Hidup no.51 tahun 2004 tentang baku mutu air laut untuk biota laut untuk parameter salinitas berkisar antara 33 - 34\%o. (Ruswahyuni, 2014) menyatakan bahwa, apabila kisaran salinitas di suatu perairan berkisar antara $23 \%$ - $26 \%$, maka akan berakibat pada perubahan pigmen warna, duri-duri akan rontok, dan bulu babi akan menjadi tidak aktif, tidak mau makan dan pada akhirnya akan mengalami kematian setelah beberapa hari. Salinitas merupakan nilai yang menunjukkan banyaknya kandungan garam garam terlarut menyusun suatu perairan. Sebaran salinitas dilaut dipengaruhi oleh beberapa faktor seperti pola sirkulasi air, penguapan, curah hujan dan aliran sungai (nontji, 2007) dan nilai salinitas ini masih layak bagi kelangsungan hidup bulu babi, hal ini sesuai dengan pernyataan vonk et, al. (2008), bahwa kisaran salinitas bagi kehidupan bulu babi dengan kisaran salinitas $33-34 \%$.

\section{KESIMPULAN DAN SARAN}

\subsection{Kesimpulan}

Berdasarkan penelitian yang telah dilakukan dapat disimpulkan sebagai berikut: Keragaman bulu babi diperairan pantai pulau merah paling tinggi Trineustes gratilla dengan nilai keragaman 3,5. Echinometra mathaei dengan nilai keragaman paling tinggi 0,52. Diadema sitosum dengan nilai keragaman tertinggi 3,3 dan Sea urchin dengan nilai keragaman tertinggi 2,11. Keseragaman bulubabi diperairan pantai pulau merah paling tinggi Trineustes gratilla dengan 
nilaikeseragaman 1, Echinometra mathaei dengan nilai keseragaman paling tinggi0,22.Diadema sitosum dengan nilai keseragaman tertinggi 1. Sea urchin dengannilai keseragaman tertinggi dengan nilai 0,67. Dominansi bulu babi diperairanpantai pulau merah paling tinggi Echinometra mathaei dengan nilai dominansi0,664. Trineustes gratilla dengan nilai dominansi tertingi dengan nilai 0,04.Diadema sitosum dengan nilai dominansi tertinggi dengan nilai 0,04. Sea urchindengan nilai dominansi tertinggi dengan nilai 0,015 .

\section{REFERENSI}

Alfiati N, Djuwito, haeruddin 2007. Buku Ajar Mata Kuliah Avertebrata Air. Universitas Diponegoro. Semarang.

Anwar Chairul. 2015.Bioekologi Bulu Babi (Echinoidea) di Perairan Laut Teluk Dalam Desa Malang Rapat Kecamatan Gunung Kijang Kabupaten Bintan.

Ayyagari, A, dan Kondamundi, R, B. 2014. Ecological Significance Of The Association Between Stomopneustes Variolaris (Echinoidea) And Lumbrinerislatreilli (Polychaeta) From Visakhapatnam Coast India. Jurnal of Marine Biologi. India

Arnold dan birtles 1989. Taksonomi Avertebrata Pengantar Praktikum Laboratorium, UI-PRESS. Jakarta.

Aziz, A, 1987. Makanan dan Cara Makan Berbagai Jenis Bulu Babi. Jurnal Osean. Volume 12(4)

Darsono, P. Dan. A. Aziz. 2002. Komunitas ekhinodermata dari beberapa pulau didaerah Sulawesi Utara. Majalah Ilmu Kelautan 26 (7): 77-88.

Aziz, A. 1994. Tingkah Laku Bulu Babi Di Padang Lamun. Balai Penelitian Biologi Laut, Pusat Penelitian Dan Pengembangan Oseanologi-LIPI, Jakarta.

Barnes,Robert D. (1982). Invertebrate Zoology. Philadelphia, PA: Holt-Saunders International

Bengen, D. G. 2004. Ekosistem Dan Sumberdaya Alam Pesisir Dan Laut Serta Prinsip Pengelolaanya. Pusat Kajian Sumberdya Pesisir dan Lautan. IPB. Bogor.

Bernard. 1977. Keanekaragaman Dan Dominansi Komunitas Bulu Babi (Echinodea) Di Perairan Pulau Menjangan Kawasan Nasional Bali Barat, sains dan teknologi.,2(2)

Brotowidjoyo. 1993. Keanekaragaman Hayati Laut. Gramedia Pustaka Utama. Jakarta.

Colemon 1991Umur dan Pertumbuhan Bulu Babi Diadema setosum Leske di Perairan Terumbu karang Gugus Pulau Pari, Pulau-Pulau Seribu. Puslitbang 
Oseanologi LIPI. Jakarta.

Dahuri, R. 2003. Pengelolaan Sumberdaya Wilayah Pesisirdan Lautan Secara

Terpadu. Pradnya Paramita. Jakarta.

Darsono, P. 1986. Mengenal Perikanan Bulu Babi. Oseana 8 (5): 21 - 26.

Darmono. 1995.Sebaran dan Kepadatan Bulu Babi Di Perairan Kepulauan Padaido

Biak Irian Jaya. Prosiding Seminar Laut Nasional III. Ikatan Sarjana

Oseanologi Indonesia. Jakarta.

Fachrul, F. M. 2007. Metode Sampling Bioekologi. bumi aksara. jakarta

Jasin, M. 1992. Zoology Invertebarata.Sinar Wijaya. Surabaya. 278 hal.

Jumanto. 2013. Struktur Komunitas Echinodermata Dipadang Lamun Perairan Desa

Pengudang Kecamatan Teluk Sebong Kabupaten Bintan Provinsi Kepulauan

Riau. Skripsi, Universitas Maritim Raja Ali Haji, Tanjung Pinang.

Nontji, A. 2007. Laut Nusantara, Djambatan, Jakarta

Nybakken. J. W. 1992. Biologi Laut, Suatu Pendekatan Ekologi. ( Terjemahan ) PT

Gramedia: Jakarta

Nystrom et, al. 2000. Biologi Laut, Suatu Pendekatan Ekologis. PT Gramedia

Pustaka, Jakarta $458 \mathrm{Hlm}$. (Diterjemahkan Oleh M.Eidmann, et al).

Odum, E.P. 1998. Fundamental of ecology. W.E. Saunders, Philadelphia, USA:

$574 \mathrm{pp}$.

Puspitasari, Suryanti, dan Ruswahyuni. 2014. Studi Taksonomi Bintang Laut (Asteroidea, Echinodermata) Dari Kepulauan Karimunjawa, Jepara, of Management of Aquatic Resources., 1(1), 7.

Radjab, AW. 2004. Sebaran dan kepadatan bulu babi di perairan Kepulauan

Padaido, Biak Irian Jaya. Dalam: Setyawan, W.B., Y. Witasari, Z. Arifin, O.S.R. Ongkosongo, S. Birowo. Pros. Sem. Laut NasionalIII, Jakarta.

Rani Triana. 2015. Identifikasi Echinodermata di selatan Pulau Tikus, Gugusan Pulau Pari, Kepulauan Seribu, Jakarta

Ratna F D. 2002. Pengaruh penambahan gula dan lama fermentasi terhadap mutu pasta fermentasi gonad bulu babi Echinoidea dengan Lactobacillus plantarum sebagai kultur starter [skripsi].Bogor :Departemen Teknologi Hasil Perairan. Fakultas Perikanan dan Ilmu Kelautan. Institut Pertanian Bogor.

Romimohtarto, K. dan S Juwana. 2005. Biologi Laut: Ilmu Pengetahuan Tentang

Biologi Laut.Djambatan. Jakarta. 540 hal.

Soegianto, A. 1994. Ekologi Kuantitatif. Usaha Nasional. Surabaya.

Sugiarto, H dan Supardi. 1995. BeberapaCatatan Tentang Bulu Babi MargaDiadema. Balai Penelitian BiologiLaut, Pusat Penelitian danPengembangan OseanologLIPI.Jakarta.Oseana 20 (4): 35.

Thamrin, Y. J. Setiawan dan S. H. Siregar. 2011. Analisis Bulu Babi Diademasetosum Pada Kondisi Terumbu Karang Berbeda di Desa Mapur Kepulauan Riau. Jurnal IlmuLingkungan Universitas Riau. 5(1) :45- 48.

Trinidad. 1989. Analisis Ekosistem Terumbu Karang Di Pulau Menjangan Kawasan Taman Nasional Bali Barat. Laporan Penelitian DIPA. Universitas Pendidikan 
Ganesha. Bali.

Yusron E. 2009. Keanekaragaman Jenis Ekhinodermata Di Perairan Teluk Kuta, Nusatenggarabarat. Jurnal makara sains $13(1)=45-49$ 